period of the first flowering of plants, and the first appearance of migratory birds, insects, and other animals of the summer season.

THE last volume (XIX.) of the Transactions of the Imperial Zoological-Botanical Society of Vienna contains, among its more important articles, contributions to the flora of Greece and Crete, by Dr. E. Weiss; a monograph of the genus Botrychium, by Dr. J. Milde (reducing the thirteen species in Moore's Index Filicum to tex); anatomical investigation of Pleurophyllidia formosa, by $R$. Bergh; a second contribution to the flora of Lower Austria, by Dr. A. Neilreich: observations on the metamorphosis of insects in the light of the theory of descent, by F. Brauer (a thoroughly Darwinian article); contributions to Hymenopterology, by Dr. J. Kriechbaumer; descriptions of several Myriapods in the Museum of Vienna, by MM. A. Humbert and $H$. de Saussure; the Lichens of the Tyrol, by F. Amold; zoological notes, by G. Ritter von Frauenfeld; contributions to the Fish-fauna of Trans-baikal, by B. N. Dybowski.

In the "Arbeiten aus der Kiel Institut" we observe that Klünder has been making further investigations into the time occupied in muscular contraction. His experiments have been conducted with a pendulum chronoscope constructed by Hensen. The contraction is traced on a reddened glass plate attached to the arm of a tuning fork, with which it therefore vibrates when this is sounded. The curve described is consequently a sintous line, its ascending and descending portion decussating. If a vertical median line be drawn on the plate when at rest, the measurements can bc examined and compared. These give for the stage of latent excitation a value of $\frac{3}{4} \frac{3}{0}$ ths of a second, which, when the muscle is weighted or exhausted, may rise to more than $0^{\circ}$ or sec. Antecedent extension diminishes the duration of this period, as Helmholtz had already remarked. The proper curve of contraction exhibits itself in its middle part as a curved line modified by the elasticity of the muscle. The muscle is quite inactive towards the end of contraction, as shown by the form of the extremitics of the curve. The greatest increase in rapidity occurs in the ascending portion of the curve, which corresponds to the greatest development of force in the muscle which is between the 3 rd and 4 th $\mathrm{I}-400$ of a sec., the absolute greatest rapidity of the ascent is in the 8 th $\mathrm{I}-400 \mathrm{sec}$. The form of the curve is, considerably changed if a heavy weight is appended to the muscle, the period of elevation as well as the fall being both longer. The retardation occurs principally at the commencement of the elevation, at which period the rapidity only slowly increases, as compared with its usual rate.

\section{THE COMING TRANSITS OF VENUS*}

TRANSITS of Venus over the disc of the sun have more than any other celestial phenomena occupied the attention and called forth the energies of the astronomical world. In the last century they furnished the only means known of learning the distance of the sun with an approach to accuracy, and were therefore looked for with an interest corresponding to the importance of this element. Although other methods of arriving at this knowledge with equal accuracy are now known, the rarity of the phenomenon in question insures for it an amount of attention which no other system of observation can command. As the rival method, that of observations of Mars at favourable times, requires, equally with this, the general co-operation of astronomers, the power of securing this co-operation does in itself give the Transits of Venus an advantage they would not otherwise possess.

Although the next transit does not occur for four years, the preliminary arrangements for its observation are already being made by the governmental and scientific organisations of Europe.

* Substance of a paper read before the Thirteenth Annual Session of the Amencan Academy of Sciences, held at Washington, by Prof. Simon Newcomb. (The original paper was illustrated by diagrams.)
It is not likely that our Government will be backward in furnishing the means to enable its astronomers to take part in this work. The principal dangers are, I apprehend, those of setting out with insufficient preparation, with unmatured plans of observation, and without a good system of co-operation among the several parties. For this reason I beg leave to call the attention of the Academy to a discussion of the measures by which we may hope for an accurate result.

In planning determinations of the solar parallax from the Transits of Venus, it has hitherto been the custom to depend entirely upon the observations of the internal contact of the limbs of the sun and planet proposed by Halley. It is a little remarkable, that while astronomical observations in general have attained a degree of accuracy wholly unthought of in the time of Halley, this particular observation has never beell made with a precision at all approaching that which Halley believed that he himself had actually attained. In his paper he states that he was sure of the time of the internal contact of Mercury and the sun within a second. The latest observations of a transit of Mercury, made in November 1868, are, as we shall presently see, uncertain by several seconds. It is also well known that the observations of the last transit of Venus, that of June 1769 , failed to fix the solar parallax with the certainty which was looked for, the result of the standard discussion being now known to be erroneous by one-thirtieth of its entire amount. One of the first steps to carry out the object of the present paper will be an inquiry into the causes of this failure, and into the different views which have been held respecting it.

The discrepancies which have always been found in the class of observations referred to, when the results of different observers have been compared, has been generally attributed to the effect of irradiation. The phenomenon of irradiation presents itself in this form: When we view a bright body, projected upon a dark ground, the apparent contour of the bright body projects beyond its actual contour. The highest phenomenal generalisation of irradiation which I am aware of having been reached is this: A lucid point, however viewed, presents itself to the sense, not as a mathematical point, but as a surface of appreciable extent. A bright body being composed of an infinity of lucid points, its apparent enlargement is an evident result of the law just cited.

[The speaker here drew a number of diagrams for the purpose of illustrating his theory.]

The following diagrams show the effect of this law upon the time of interval contact of a planet with the disc of the sun. The planet being supposed to approach the solar disc, Fig. I shows the geometrical form of a portion of the apparent surface of the sun, or the phenomenon as it.would be if there were no irradiation immediately before the moment of internal contact. Fig. 2 shows the corresponding appearance immediately after the contact. To indicate the effect of irradiation, or to show the phenomenon as it will actually appear on the theory of irradiation, we have only to draw an infinity of minute circles for each point of the sun's disc visible around the planet to indicate the apparent phenomenon. The effect of this is shown in Figs. $1 a$ and $2 a$. The exceedingly thin thread shown in Fig. $I$ is thus thickened as in $\mathrm{I} a$, and the sharp cusps of Fig. 2 are rounded off as shown in Fig. 2a. The apparent radius of the planet is diminished by an amount equal to the radius of the circle of irradiation, and the radius of the sun is increased by the same amount. Comparing Figs. $\mathrm{I} a$ and $z a$, it will be seen that the moment of internal contact is marked by the formation of a ligament, or "black drop," between the limbs of the sun and the planet. This formation is of so marked a charaster that it has been generally supposed there could be little doubt of the moment of its occurrence. The remarks of the observers have given colour to this supposition, the black drop being generally described as appearing suddenly at a definite moment.

Examining Fig. $2 a$, it will be seen that the planet still appears entirely within the disc of the sun. The geometrical circle which bounds the latter, and that which bounds the planet, instead of touching, are separated by an amount equal to double the irradiation. And, when they finally do touch, neither of them will be visible at the point of contact. The estimate of the moment of contact must therefore be very rough, the means of estimating being far less accurate than those afforded by a common filar micrometer. In the actual case the eye has to continue the two circles to the point of contact by estimation, through a distance depending on the amount of irradiation, while measures with a micrometer are made by actual contact of a wire with a disc. Such estimates have, therefore, been 
generally rejected by investigators, not only from their necessary Inaccuracy, but because the time of "apparent contact" depends upon the amount of irradiation, which varies with the observer and the telescope. If there is no irradiation at all, the time of apparent contact and that of true contact will be the same, as shown in Fig. 2, while, when the cusps are enlarged by irradiation, apparent contact will not occur until the planet has moved through a space equal to double the irradiation.

Let us return to the phenomenon at actual contact. According to the theory as it has been presented, the formation or wipture of the black ligament connecting the clark body of Venus with the dark ground of the sky is a well-marked phenomenon, occurring at the moment of true internal contact. This was, I believe, the received theory until Wolf and André made their experiments on artificial transits in the autumn and winter of 1868 and 1869 . They announced, as a result of these experiments, that the formation of the ligament was not contemporaneous with the occurrence of internal contact, but followed It at the ingress of the planet, and preceded it at egress. In other words, it appeared while the threacl of light was still $\mathrm{cmm}$ plete. They furthermore announced that with a good telescope the ligament did not appear at all, but the thread of light hetwcen Venus and the sin broke off by becoming indefinitely thin.

The result is not difficult to account for. Irradiation has already lcen described as a spreading of the light emitted from each point cf the surface viewed, so that every such point appears as a small circle. The obvious effect of this spreacting is a dilution of the light cmitted by a lyuninous thread, whenever the diamcter of the thrcarl is ress than that of the circle of irradiation. In consequence of this dilution, the thread may be invisible while it is really of sensible thickness, a given amount of light producing a greater effect on the eye the more it is concentrater. Since the threar of light must seem to break when it becomes invisille at its thinnest point, the formation or rupture of the thread farks, not the noment of actual contact, but the moment at which the thrcad of light becomes so thick as to be visible, or so thin as to he invisible. The greater the irradiation, and the worsc the definition, the thicker will be the thread at this moment.

An intcresting crecrnation, illustrative of this point, was made by Liais at Rio Janeiro, churing the transit of Mercury of November $I, x \in 68$. He had two telescopes, one much smaller than the other. Ife watched the planet sin the small one till it seemed to touch the disc of the sun, then looking into the large one, he s?w a thread of light distinctly between the planet and the sun, snd they did not ically touch until several seconds later.

lefcrence to the figures will make it clear that there is no generic difference between the phenomenon commonly callcd the jupturc of the black drop and that of the formation of the thrcad of light. If the bright cusps are much rounded, as in Fig. $x a$, the appearance betriecn them is necessarily that of a drop, while if they are seen in their true sharpness, as in Fig. $r$, the form of the clrop will not appen. It has been shown that with different instruments the phenomenon of coutact may exhibit every graclation between these cxtremes. The only well-defined phenomenon which all can see is the meeting of the bright cusps and the consequent formation of the thread of light at ingress, and the rupture of the thread at egress.

To recapitulate our conclusions-

I. The movement of observed internal contact at ingress is that at which the thread of light between Venus and the sun becomes thick enough to be visible.

2. The least visible, thickness varies with the observer and the instrument, and, perhaps, with the state of the atmosphere.

3. The apparent initial thickness of the thread varies with the irradiation of the telescope.

Two questions are now to be discussed. The observed times varying with the observer and the instrument, we must know how wide the variation may be. If it be wide enough to render uncertain the results of observation, we shall inquire how its injurious effects may be obviated.

The first question can be decided only by comparison of the observations of different observers upon one and the same phenomenon. For such cotriparison I shall select the observations of the egress of Mercury on the occasion of its last transit over the disc of the sun. This selection is made for the reason that this egress was observed by a great number of experienced observers with the best instruments, while former transits, whether of Venus or Mercury, have been observed less extensively or at a time when practical astronomy was far from its present state of perfection, and that the transit in question would therefore furnish much better data of judging what we might expect in futurc observations. The comparison was made in the following way :- I selected from the "Astronomische Nachrichten," the "Monthly Notices of the Royal Astronomical Society." and the "Comptes Rendus," all the observations of internal contact at egress which there was reason to believe related to the breaking of the thread of light, and which were made at stations of known longitude. Each observation was then reduced to Greenwich time, and to the centre of the earth.

From these comparisons it appears that the contact was first seen by Le Verrier, at Marseilles, at two seconds before nine o'clock, Greenwich time. In one second more it was seen by Rayet at Paris, Oppolzer at Vienna, Lynn at Greenwich, and Kaiser at Leyclen. The times, noted by twenty other observers, are scattered very evenly over the following fifteen seconds. Kam and Kaiser, at Leyden, did nat see the contact until nineteen and twenty-four seconds past nine.

It thus appears that among the best observers, asing the best instruments, the:e is a difference exceeding twenty seconds between the times of noting confact. This difference corresponds to more than a second of arc, so that really these observations were scarcely made with more accuracy than measures under favourable circumstances with a micrometer, and are not therefore to be relied on. But a great addition to the accuracy of the determination could be made by measures of the distance of the cusps, while the planet was entering wpon the disc of the sum. It would tend greatly to the accuracy of the results, if the olscrvers should meet beforehand with the telescopes they were actually to use in observing the transit and male observations in common on artificial transits. It would be a comparatively simple operation to erect an artificial representation of the sun's disc at the distance of a few hundred yards, and to have an artificial planet moved over it by clock-work. The actual time of contact conld be cletermined by electricity, and the relative positions of the planct and the disc by actual measurement. With this apparatus it would be easy to determine the personal errors to which each observer was liable, and these errors would approximately represent those of the observations of actual transit.

Still it would be very unsafe to trust mainly to any determination of internal contact. Understanding the uncertainty of such determinations, the German astronomers have proposed to trust to measures with a heliometer, made while the planet is crossing the disc. The use of a sufficient number of heliometers would be both clifficult and expensive, and I think we have an entirely sntisfactory substitute in photography. Indeed, Mr. De la Rue has proposed ta determine the moment of internal contact by photography. But the result would be subject to the same uncertainty which affects optical observations-the photograph which first shows contact will not be that taken when the thread of light between Venus and the sun's disc was first completed, but the first taken after it became thick enough to affect the piate, and this thickness is more variable and uncertain than the thickness necessary to affect the eye. We know vary well that a baziness of the sky which very slightly diminishes the apparent brilliancy of the sum, will very materially cut of the actinic rays, and the photographic plate has not the power of adjustment which the eye has.

But, although we cannot determine contacts by photography, I conceive that we may thereby be able to measure the distance of the centres of Venus and the sun with great accuracy. Having a photograph of the sun with Venus on its disc, we can, with a suitable micrometer, fix the position of the centre af each body with great precision. We can then measure the distance of the centres in inches with corresponding precision. All we then want is the valute in arc of an inch on the photograph plate. This determination is not without difficulty. It will not do to trust the measured diameters of the images of the sun, because they are affected by irradiation, just as the optical image is. If the plates were nearly of the same size, and the ratio of the diameters of Venus and the sun the same in both plates, it would be safe to assume that they were equally affected by irradiation. But should any show itself, it would not be safe to assume that the light of the sun encroached equally upon the dark ground of Venus and upon the sky, because it is so much fainter near the border.

If the photographic telescope were furnished with clock-work, it would be advisable to take several photographs of the Pleiades belt, before and after the transit, to furnish an accurate standarcl 
of comparison free from the danger of systematic error. There is little doubt that if the telescopes and operators practise together, either before or after the transit; data may be obtained for a satisfactory solution of the problem in question.

To attain the object of the present paper, it is not necessary to enter into details respecting choice of stations and plans of observation. I have endeavoured to show that no valuable result is to be expected from hastily-organised and hurriedly-equipped expeditions; that every step in planning the observations requires careful consideration, and that in all the preparatory arrangements we should make haste very slowly. I make this presentation with the hope that the Academy will take such action in the matter as may seem proper and desirable.

\section{NORTH OF ENGLAND INSTITUTE OF MINING $A N D$ DECHANICAL ENGINEERS-MEETING AT GLASGOW}

$A$ FTER having had an existence of some fifteen or sixteen years, during which it has done a large amount of scientific and thoroughgoing practical work, this North Country Institute has just deviated from its usual practice of holding its meetings in Newcastle-on-Tyne, and, with the co-operation of the Scottish Engineers and Shipbuilders ${ }^{*}$ Association, has held a very successful meeting in Glasgow, the centre of the great Scottish coal-field, and the head-quarters of the mining and engineering industries of Scotland, and of the shipbuilding industry of the United Kingdom. The meeting began on Tuesday, the gth of August, and extended over four days. On the opening day the Lord Provost of the City of Glasgow received and formally welcomed the members of the North of England Institute in name of the citizens and the Institution of Engineers and Shipbuilders; and thereafter the chair was taken by Mr. E. F. Boyd, President of the North of England Institute, and the business of the meeting commenced.

There were set down for reading and discussion no fewer than eighteen papers, the subjects treated of being all directly connected with mining and mechanical engineering. Only three papers were overtaken on the first day, when it was found that the time for adjournment had arived. The afternoon was spent by the members in visiting various engineering and shipbuilding works, and other manufacturing establishments, which were freely thrown open to inspection by their respective proprietors.

We shall here briefly indicale the nature of the papers read and discussed at Tuesday's sitting of the Institute.

I. "On the Geology of the Coal Measures of Scotland," by Mr. James Geikie, district surveyor of the Geological Survey of Scotland. The author described, first, the calciferous sandstone series, which, when typically developed, consists of two groups of strata, the lower pointing to the prevalence of marine conditions during the deposition of the red sandstones and conglomerates, and the upper showing that during its accumulation marine and brackish water conditions alternated with the occasional appearance of land surfaces. Volcanoes were somewhat prevalent during the deposition of both groups. Second: The caiboniferous limestone series, consisting of a lower group indicating marine conditions and occasional old land surfaces; a middle group indicating frequent land surfaces, and alternate brackish water and marine conditions; and an upper group pointing chiefly to lower marine conditions, with occasionai brackish water deposits and a few old land surfaces: both submarine and subaërial volcanoes very active during the deposition of the whole series. Third: The millstone grit, deposited under almost exclusively marine conditions. Fourth : The coal measures; showing a prevalence of brackish or freshwater conditions, with abundant land surfaces, and speaking also of occasional inroads of the sea. No igneous rocks contemporary with the coal measures or millstone grit. Fifth : Intrusive rocks of three classes, namely, intrusive sheets, referable to close of "coal measures" group; bosses or pipes of tuff or agglomerate, probably of Permian age; and dykes of dolexite of Miocene pos. Sixth : Two systems of failts of different ages; the oldest striking N.E. and S.W., and the other, a double set, striking approximately $\mathrm{E}$. and $\mathrm{W}$. and $\mathrm{N}$, and $\mathrm{S}$. Mr. Geikie, in concltiding, referred to the exceeding richness of the variety shown by the phenomena of the Scottish carboniferous formation, and said he had no hesitation in affirming that, when the palæontological and geological history of the carboniferous rocks of Scotland were worked out, there would be prepared one of the most important chapters in the physical history of the country.
2. "On the Magnetic Ironstone of Rosedale Abbey, Cleveland;" by Mr. John Marley, M.E. This paper treated of the extraordinary deposit of magnetic ironstone which occurs at Rosedale West, and forms a very peculiar feature in the famous Cleveland ironstone, regarding which various papers have been published since 1857 , when Mr. Marley first direw the attention of scientific men to it. The magnetic stone oceurs quite isolated in two troughs, one of which is go feet deep, and it contains, iui the best specimens, from 42 to 50 per cent. of metallic iron: In 1857 its extent was unproved; but it was believed to be very great, but this is now known not to be the case, from the results of recent borings and explorings which Mr. Marley fully detailed. The author explained the curious geological relationship which the magnetic store bears to the top bed of the lias ironstone of Cleveland. The troughs lie east and west. Icebergs and glacial action were, in his opinion, in no way connected with the induction of the magnetic state, nor yet with the formation of the troughs: The deposits are not two beds of regular strata, nor are they veins, as no fissures have yet been found in the bottom of the troughs, although they have been diligently looked for. Mr. Isaac Lowthian Bell supplemented Mr. Marleý's description by giving the results of a visit which he had paid to Rosedale, and stated that the magnetic ore conld not be the result of volcanic action, as carbon was always contained in the analysis; as also water of hydration and a notable quantity of carbon.

3. "On the Duty of Cornish and other Pumping Engines," by Mr. J. B. Simpson. This paper was of especial interest on account of the subject treated of in it having a most intimate connection with the economy of fuel and the duration of the coal supply. After describing fully a Cornish engine recently erected in the Newcastle district, the author entered upon an examination of the details of twelve different kinds of engines; and compared their merits with those of the Cornish engine. In conclusion, he said that taking those engines into consideration; their average duty corresponded to a consumption of I 113 . o coal per horse-power per hour. Were a duty of $4 \mathrm{lb}$, obtained, the saving in these engines alone would represent 40,000 tons of coal per annum, or, at $3 s$. per ton, 6,000 l. The assumed total horse-power of pumping-engines in the $\mathrm{New}$ castle district is about 10,000 , and from this the amount of the possible annual saving may easily be calculated. In many places coal may not be worth $3 s$. per ton at the pit mouth, but in the majority of cases its value is much greater. It is too much the practice to regard coal at the colliery as of little or no value, and that the extra rolb. or 12lb. per horse-power per hcur is not worthy of consideration. But fuel is not the only pecuniary part of the question, as extra consumption of coal means additional water, additional repairs, additional wear and tear, and additional manual labour-and these in the aggregate are very serious items of cost. The time does not seem far off when, in pumping and other colliery engines, the effective duty of $2 \mathrm{lb}$. or $3^{\mathrm{ib}} \mathrm{b}$. of coal per horse-power per hour will be considered as important as in the engines of London water-works and ocean steam-ships.

In the evening of Tuestlay a conversazione was held in the Corporation Galleries. The east and west halls were occupied by numerous collections of objects-geological, palæontological mineralogical, metallurgical, chemical, mechanical, engineering, mining, \& ., together with a magnificent display of photographs, by Annan, of the Old Glasgow College, and various engineering works and Clyde-built ships. This exhibition was of immense scientific and industrial interest, and was at once the most extensive and valuable that has been held in Glasgow for many years. Advantage was taken of this evening's meeting to perform an interesting ceremony, namely, the presentation of a marble bust to Professor W. J. Macquorn Rankine, C.E., F.R.S., first president of the Institution of Engineers in Scotland, as a token of the appreciation and esteem of the members. A duplicate copy of the bust was also presented to the institution as a memorial of the Professor's labours in promoting the success of the institution. In the Large Upper Gallery there was an exceedingly interesting exhibition by means of the oxy-hydrogen light, of sections of fossil corals, by Mr. James Thomson, F.G.S., a gentleman who has of late years gone most extensively and enthusiastically into the study of fossil corals, and made it almost entirely his own; and so fully persuaded are palæontologists of the great value of his investigations, that Mr. Thomson is assisted by a grant from the British Association, at the forthconing meeting of which he is to present a second report and exhibit his wonderful series of specimens: 